\title{
Reductive enzymatic dynamic kinetic resolution affording 115 g/L (S)-2-phenylpropanol
}

Christian Rapp', Simone Pival-Marko ${ }^{1,3}$, Erika Tassano ${ }^{2}$, Bernd Nidetzky ${ }^{1,3}$ and Regina Kratzer ${ }^{1 *}$

\begin{abstract}
Background: Published biocatalytic routes for accessing enantiopure 2-phenylpropanol using oxidoreductases afforded maximal product titers of only $80 \mathrm{mM}$. Enzyme deactivation was identified as the major limitation and was attributed to adduct formation of the aldehyde substrate with amino acid residues of the reductase.

Results: A single point mutant of Candida tenuis xylose reductase (CTXR D51A) with very high catalytic efficiency $\left(43 \cdot 10^{3} \mathrm{~s}^{-1} \mathrm{M}^{-1}\right)$ for $(S)$-2-phenylpropanal was found. The enzyme showed high enantioselectivity for the (S)-enantiomer but was deactivated by $0.5 \mathrm{mM}$ substrate within $2 \mathrm{~h}$. A whole-cell biocatalyst expressing the engineered reductase and a yeast formate dehydrogenase for $\mathrm{NADH}$-recycling provided substantial stabilization of the reductase. The relatively slow in situ racemization of 2-phenylpropanal and the still limited biocatalyst stability required a subtle adjustment of the substrate-to-catalyst ratio. A value of $3.4 \mathrm{~g}_{\text {substrate }} / \mathrm{g}_{\text {cell-dry-weight }}$ was selected as a suitable compromise between product ee and the conversion ratio. A catalyst loading of $40 \mathrm{~g}_{\text {cell-dry-weight }}$ was used to convert $1 \mathrm{M}$ racemic 2-phenylpropanal into $843 \mathrm{mM}(115 \mathrm{~g} / \mathrm{L})(\mathrm{S})$-phenylpropanol with $93.1 \%$ ee.
\end{abstract}

Conclusion: The current industrial production of profenols mainly relies on hydrolases. The bioreduction route established here represents an alternative method for the production of profenols that is competitive with hydrolasecatalyzed kinetic resolutions.

Keywords: Enantiopure 2-aryl-1-propanol, Reductive dynamic kinetic resolution, Biocatalyst stability, Aldo-keto reductase engineering

\section{Highlights}

- The D51A mutant of Candida tenuis xylose reductase showed a 270-fold higher enzymatic activity and improved enantioselectivity for (S)-2-phenylpropanal.

- Use of a whole-cell catalyst stabilized the enzyme $>1000$-fold under reaction conditions.

- Efficient kinetic resolution of racemic 2-phenylpropanal by the whole-cell catalyst was demonstrated.

\footnotetext{
${ }^{*}$ Correspondence: regina.kratzer@tugraz.at

${ }^{1}$ Institute of Biotechnology and Biochemical Engineering, Graz University of Technology, NAWI Graz, 8010 Graz, Austria

Full list of author information is available at the end of the article
}

(S)-2-phenylpropanol was produced with a titer of $843 \mathrm{mM}(115 \mathrm{~g} / \mathrm{L})$ and $93.1 \% e e$.

- The substrate-to-biocatalyst ratio was the main factor determining the enantiopurity and final titer of the product.

\section{Background}

2-Aryl-1-propanols are crucial synthons of profen-type non-steroidal anti-inflammatory drugs (NSAIDs) [1]. The simplest representative of this class, 2-phenylpropanol, has an odor resembling lilac or hyacinth, and is used as a fragrance ingredient in personal care products, as well as a precursor in the synthesis of further fragrances $[2$, 
3]. The different biological activities and odors of $R$ - and $S$-profens have inspired studies on the production of optically pure 2-aryl-1-propanols. A number of biocatalytic routes have been proposed over the years, including kinetic resolutions by hydrolases, nitrile-converting enzymes or oxidases, asymmetrization of prochiral precursors through enzymatic decarboxylation, and isomerization by styrene oxide isomerase. Kinetic resolutions using hydrolases and oxidoreductases are the two most mature strategies (reviewed in [4]). The economic attractiveness of kinetic resolutions, which are restricted to maximally $50 \%$ yield, can be increased by in situ racemization of the unused antipode, resulting in dynamic kinetic resolutions (DKR). DKR strategies exploiting hydrolases and oxidoreductases make use of the relatively fast racemization of 2-aryl-1-propanoic acids/esters and 2-aryl-1-propanals (Fig. 1). Hydrolase-catalyzed kinetic resolutions were the first biocatalytic routes towards enantiopure profens, and numerous lipases and esterases have been tested for their enantioselectivities towards several profens [5]. Product concentrations of $0.5 \mathrm{M}$ and enantiopurities of up to $99 \% e e$ were reported, leading to the application of hydrolases at the industrial scale [6,7]. Although hydrolases remain attractive in terms of their process performance, they offer limited opportunities to valorize intellectual property [4]. Oxidoreductases are an interesting alternative, but the published biocatalytic routes for accessing chiral 2-aryl-1-propanols using oxidoreductases show markedly lower product concentrations of maximally $80 \mathrm{mM}[4,8-17]$. Here, we report a reductive enzymatic dynamic kinetic resolution for the preparation of (S)-2-phenylpropanol. The xylose reductase from Candida tenuis (CtXR, aldo-keto reductase superfamily) showed a basal activity with rac-2-phenylpropanal and moderate preference for the $(S)$-enantiomer. We investigated five enzyme variants with single point mutations in close vicinity to the stereocenter of 2-phenylpropanal. The D51A mutant of CtXR showed high catalytic activity with excellent enantioselectivity for (S)-2-phenylpropanal, and was integrated into a reductive whole-cell catalyst based on E. coli. Reaction optimization resulted in high enantioselectivity and product concentration at full conversion. The reductive enzymatic dynamic kinetic resolution established in this study is comparable with lipase-based processes in terms of product concentration, offering a viable alternative for industrial applications.

\section{Results}

CtXR, which converts xylose to xylitol in the central sugar metabolism of Candida tenuis, is a member of the aldo-keto reductase (AKR) superfamily. Like many other AKRs, CtXR has broad substrate specificity, and several substrate-binding site mutants with improved specificity for aromatic ketones were used in the synthesis of $(R)$ ethyl mandelates and $(S)$-phenylethanols $[18,19]$. However, the application of $C t \mathrm{XR}$ as an industrial biocatalyst was hindered by its moderate catalytic activity and low stability. Motivated by a moderate intrinsic activity of wild-type $C t \mathrm{XR}$ on $\mathrm{rac}$-2-phenylpropanal $\left(k_{\mathrm{cat}} / K_{\mathrm{m}, \mathrm{rac}}\right.$ $130 \mathrm{~s}^{-1} \mathrm{M}^{-1}, k_{\mathrm{cat}} 0.05 \mathrm{~s}^{-1}$ ), we tested a number of single point mutations targeting the substrate-binding site for their effects on the activity and enantioselectivity of the enzyme in the reduction of 2-phenylpropanal.

\section{CtXR mutants}

The substrate-binding cavity of aldo-keto reductases is mainly formed by residues from three large and flexible loops [20,21]. Loop flexibility provides the structural basis for the relaxed substrate specificity, but complicates rational engineering [22]. A model of the binding mode of the natural substrate D-xylose (open chain form) indicated that the $\mathrm{C}-1$ of xylose is positioned within hydridetransfer distance above the C-4 of nicotinamide, with a hydrogen bond between the carbonyl oxygen and the general acid catalyst Tyr-52. In this model, the aldehyde hydrogen was oriented towards the indole ring of Trp-24 and the C-2 hydroxyl interacted with Asn-310, while the hydroxyl groups of C3, C4 and C5 interacted with Asp51 [23]. Here, we probed wild-type CtXR and individual point mutants of the main substrate recognition residues Trp-24, Asn-310 and Asp-51 as catalysts for the reduction of 2-phenylpropanal. The replacement of Trp-24 with smaller phenylalanine and tyrosine was previously shown to increase enzyme activity on bulky ketone substrates $[18,24]$. Interaction between the $N \delta 1$ of Asn310 and the $C-2(R)$ hydroxyl of sugars is considered the basis for substrate discrimination in CtXR [23, 24]. Asp51 accounts for a major part of the relative polarity of the binding site, and its substitution with alanine led to improved activity with the aromatic ketone $o$-chloroacetophenone [19].

\section{Reduction of 2-phenylpropanal by $C$ XXR variants}

Table 1 summarizes the steady-state kinetics of NADHdependent reduction of racemic and (S)-2-phenylpropanal by wild-type $C t \mathrm{XR}$ and the substrate-binding-site mutants.

Racemic substrate. The wild-type enzyme showed a $K_{\mathrm{m}, \text { rac }}$ value of $350 \mu \mathrm{M}$ and a $k_{\text {cat }}$ value of $0.05 \mathrm{~s}^{-1}$, corresponding to a specificity constant $\left(k_{\mathrm{cat}} / K_{\mathrm{m}, \mathrm{rac}}\right)$ of $130 \mathrm{~s}^{-1} \mathrm{M}^{-1}$. The mutants W24F and W24Y displayed only 8 to $10 \%$ of the wild-type activity. Although the N310A mutant had a specificity constant similar to the wild type, the N310D mutant showed no activity. CtXR D51A stood out with a $K_{\mathrm{m}, \text { rac }}$ value of $170 \mu \mathrm{M}$ 


$$
\text { rac-2-phenylpropanal }
$$<smiles>C[C@@H](C=O)c1ccccc1</smiles><smiles>COC(=O)OC1CC1CC1CC1CO</smiles><smiles>C[C@@H](C=O)c1ccccc1</smiles>

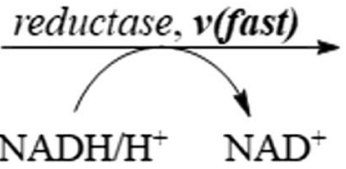

$(S)$-2-phenylpropanol

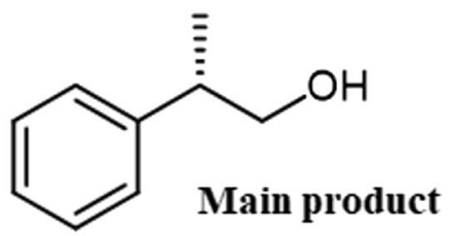

\section{(R)-2-phenylpropanol}
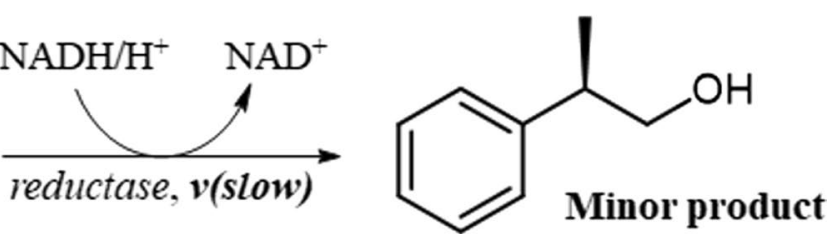

Fig. 1 Reductive enzymatic dynamic kinetic resolution of racemic 2-phenylpropanal

and a $k_{\text {cat }}$ value of $4.8 \mathrm{~s}^{-1}$, corresponding to a $k_{\text {cat }} / K_{\mathrm{m} \text {,rac }}$ of $28 \cdot 10^{3} \mathrm{~s}^{-1} \mathrm{M}^{-1}$. Hence, replacement of the charged aspartic acid with alanine led to 215 -fold higher catalytic efficiency compared to the wild type. Conversely, introduction of an additional aspartic acid in the substrate-binding pocket (N310D) completely abolished enzyme activity with 2-phenylpropanal. Enlargement of the substrate binding pocket by replacement of the bulky Trp-24 decreased the enzyme's activity towards 2-phenylpropanal.

(S)-2-phenylpropanal. Kinetic parameters obtained with the racemic substrate and (S)-2-phenylpropanal were used to calculate the optical preference ratio $\left(k_{\text {cat }} / K_{\mathrm{m}, \mathrm{S}}\right) /\left(k_{\mathrm{cat}} / K_{\mathrm{m} \text { rac }}\right)$ (Table 1$)$. The wild type showed a ratio of 1.23 with a preference for the $S$-enantiomer. The D51A mutant showed a ratio of 1.54 and hence a stronger preference for the $S$-enantiomer. The W24F, W24Y and N310A mutants displayed ratios $<1$, suggesting a preference for the $R$-enantiomer. It should be noted that the CtXR mutants showed 35 to 100 -fold reduced catalytic activity towards the natural substrate xylose [24].

We used isolated CtXR D51A in bioreductions of $0.5 \mathrm{mM}$ rac-2-phenylpropanal. The substrate $(\log P 2.11$, https://scifinder.cas.org/) displayed a maximal solubility of $0.5 \mathrm{mM}$ in the buffer $(50 \mathrm{mM}$ potassium phosphate, pH 7.0 with 25\% DMSO). Product concentrations and ee values obtained at enzyme concentrations between 360 and $0.6 \mathrm{U} / \mathrm{mL}$ are listed in Table 2 . The product $e e$ values increased with decreasing amounts of the enzyme. Unexpectedly, the reactions stopped after approximately $1 \mathrm{~h}$ and maximal product concentrations of only $\sim 80 \mu \mathrm{M}$ were achieved (for a time course see the Additional file 1: Fig. S1). We suspected that enzyme deactivation caused the low conversions and decided to use a whole-cell biocatalyst expressing CtXR D51A for further experiments.

Optimization of rac-2-phenylpropanal reduction using whole cells of $E$. coli co-expressing $C t$ XR D51A and a yeast formate dehydrogenase

Bioreductions were accomplished using whole cells of transgenic $E$. coli that were lyophilized and rehydrated in phosphate buffer. The phenylpropanal reductase and formate dehydrogenase activities of the whole-cell biocatalyst were 2200 and $154 \mathrm{U} / \mathrm{g}_{\mathrm{CDW}}$, respectively (the rac-2-phenylpropanal reduction activity was determined with $0.5 \mathrm{mM}$ rac-2-phenylpropanal). Addition of the biomass to reaction mixtures with a final substrate concentration of more than $100 \mathrm{mM}$ led to emulsification [25]. A substrate concentration of $100 \mathrm{mM}$ was converted by 4 and $10 \mathrm{~g}_{\mathrm{CDW}} / \mathrm{L}$ of the whole-cell biocatalyst to 41 and $67 \mathrm{mM}(S)$-phenylpropanol with ee-values of 95.3 and $62 \%$, respectively (Fig. 2). Next, we optimized the catalyst loading (20 and $\left.40 \mathrm{~g}_{\mathrm{CDW}} / \mathrm{L}\right)$, substrate concentration $(1$ and $2 \mathrm{M}), \mathrm{NAD}^{+}$concentration $(3,6,8,10,12$ and $14 \mathrm{mM}$ ) and cyclodextrin addition (38 and $75 \mathrm{mM}$ ) (Table 3). Our primary goal was a high product concentration, as the substrate had shown a strong deactivating effect on the isolated enzyme. Secondary goals were high product enantiopurity and a high conversion ratio. We increased the substrate concentration to $1 \mathrm{M}$ at 20 and $40 \mathrm{~g}_{\mathrm{CDW}} / \mathrm{L}$ catalyst loading. Product enantiopurity and conversion increased with higher biocatalyst concentration. A catalyst loading of $20 \mathrm{~g}_{\mathrm{CDW}} / \mathrm{L}$ led to an $e e$ value of $95.1 \%$, but the conversion ratio fell to $23 \%$. Increasing the catalyst loading to $40 \mathrm{~g}_{\mathrm{CDW}} / \mathrm{L}$ decreased the $e e$ value to $92.2 \%$ but achieved $51 \%$ conversion (Table 3 , entries 
with $3 \mathrm{mM} \mathrm{NAD}{ }^{+}$). A substrate concentration of $2 \mathrm{M}$ was too high, resulting in only low conversions of $~ 30 \%$. The step-wise addition of substrate at 0,2 and $4 \mathrm{~h}$ corresponding to a total substrate concentration of $1 \mathrm{M}$ led to conversions and product ee-values comparable to batch conversions (Table 3 ). We added higher concentrations of the coenzyme $\mathrm{NAD}^{+}(6$ to $14 \mathrm{mM})$ to reactions with $40 \mathrm{~g}_{\mathrm{CDW}} / \mathrm{L}$ and $1 \mathrm{M}$ substrate to further push the reaction towards full conversion. With 10 and $12 \mathrm{mM}$ $\mathrm{NAD}^{+}$, conversion ratios of up to $84 \%$ were reached, with ee values of 92-93\% (Table 3). The effects of catalyst loading and $\mathrm{NAD}^{+}$concentration are summarized in the Additional file 1: Fig. S2. The addition of $75 \mathrm{mM}$ 2-hydroxypropyl- $\beta$-cyclodextrin was previously shown to boost bioreductions [19]. Here, the addition of 38 or $75 \mathrm{mM}$ 2-hydroxypropyl- $\beta$-cyclodextrin had a positive effect on reactions with a catalyst loading of $20 \mathrm{~g}_{\mathrm{CDW}} / \mathrm{L}$, but it had of no significant effect on bioreductions of 1 and 2 M 2-phenylpropanal (Table 3).

\section{Reproducibility, recovery and by-products}

Replicate bioreductions $(\mathrm{N}=7)$ with $40 \mathrm{~g}_{\mathrm{CDW}} / \mathrm{L}$ and $6 \mathrm{mM} \mathrm{NAD}^{+}$showed high reproducibility with a mean conversion ratio of $62 \%$ and a standard deviation of $2.4 \%$. The enantiomeric excess was $93.3 \pm 1.1 \%$. The formation of broad peaks prevented the quantification of the aldehyde substrate by chiral reversed-phase HPLC. We therefore additionally analyzed the bioreduction samples by chiral GC-FID (Additional file 1: Fig. S4). The high reactivity of the substrate 2-phenylpropanal prompted us to investigate possible by-products generated through chemical or bio-chemical side-reactions. It was previously shown that acetophenone is formed through the degradation of rac-2-phenylpropanal by atmospheric oxygen [26]. Hydrophobic compounds were extracted from two reaction mixtures (1 M rac-phenylpropanal,
$40 \mathrm{~g}_{\mathrm{CDW}} / \mathrm{L}$ catalyst, $6 \mathrm{mM} \mathrm{NAD}+, 1 \mathrm{~mL}$ volume per reaction), after which the solvent, and possibly unreacted 2-phenylpropanal (bp $92-94^{\circ}$ ), were removed under reduced pressure. The concentrate with a weight of $203 \mathrm{mg}$ was composed of 86\% 2-phenylpropanol, 7\% acetophenone and 7\% ethyl acetate (extractant) according to ${ }^{1} \mathrm{H}-\mathrm{NMR}$ (Additional file 1: Fig. S5). We found trace amounts of 1-phenylethanol, the enzymatic reduction product of acetophenone [27]. Notably, no 2-phenylpropanal was found. The substrate was in a chemical equilibrium between rac-2-phenylpropanal and its corresponding hydrates. The previously reported enzymatic oxidation of 2-phenylpropanal hydrates to the corresponding carboxylic acids was not observed [12, 28], and no enol or aldol isoforms of the substrate were detected. The HPLC, GC and NMR analyses are shown in Additional file 1: Sects. 4, 5 and 6, respectively. The loss of substrate/product with the biomass was approximately $15 \%$ under the described reaction conditions (data not shown).

Table 2 Conversions and product ee-values for the reduction of rac-2-phenylpropanal by isolated CtXR D51A. a,b

\begin{tabular}{lll}
\hline $\mathrm{CtXR}(\mathrm{U} / \mathrm{mL})^{\mathrm{c}}$ & Phenylpropanol $(\boldsymbol{\mu M})$ & $\begin{array}{l}\text { ee }(\boldsymbol{S})- \\
\text { Phenylpropanol } \\
(\%)\end{array}$ \\
\hline D51A (20) & $76 \pm 3$ & $41 \pm 4$ \\
D51A (3.4) & $51 \pm 5$ & $98 \pm 2$ \\
D51A (0.6) & $13 \pm 5$ & $99.1 \pm 0.3$ \\
\hline
\end{tabular}

${ }^{a} \mathrm{NAD}^{+}$concentration $0.7 \mathrm{mM}$, reaction time $2 \mathrm{~h} .{ }^{\mathrm{b}}$ The phenylpropanol concentrations were measured by HPLC, the data represent the mean values of two reaction replicates and standard deviations from the mean. 'The enzyme activity $(\mathrm{U} / \mathrm{mL})$ was measured with $0.5 \mathrm{mM}$ rac-2-phenylpropanal

Table 1 Apparent kinetic parameters of wild-type CtXR and substrate-binding-site mutants in the NADH-dependent reduction of racemic and (S)-2-phenylpropanal ${ }^{a}$

\begin{tabular}{|c|c|c|c|c|c|}
\hline \multirow[b]{2}{*}{ CtXR } & \multicolumn{2}{|c|}{ rac-2-phenylpropanal } & \multicolumn{2}{|c|}{ (S)-2-phenylpropanal } & \multirow{2}{*}{$\begin{array}{l}\text { Optical preference ratio } \\
\text { (S)-aldehyde / } \\
\text { racemic aldehyde }\end{array}$} \\
\hline & $\begin{array}{l}k_{\text {cat }} / K_{\mathrm{m}, \text { rac }} \\
\left(\mathrm{s}^{-1} \mathrm{M}^{-1}\right)\end{array}$ & $\begin{array}{l}K_{\mathrm{m}, \text { rac }} \\
(\mu \mathrm{M})\end{array}$ & $\begin{array}{l}k_{\mathrm{cat}} / K_{\mathrm{m}, s_{1}} \\
\left(\mathrm{~s}^{-1} \mathrm{M}^{-1}\right)\end{array}$ & $\begin{array}{l}K_{m, s} \\
(\mu M)\end{array}$ & \\
\hline wild-type & 130 & 350 & 160 & 450 & 1.23 \\
\hline D51A & $28 \cdot 10^{3}$ & 170 & $43 \cdot 10^{3}$ & 120 & 1.54 \\
\hline W24F & $13^{\mathrm{b}}$ & N/A & 12 & N/A & 0.92 \\
\hline W24Y & $10^{\mathrm{b}}$ & N/A & 9 & N/A & 0.90 \\
\hline N310A & 88 & 280 & 68 & 330 & 0.77 \\
\hline N310D & no activity & no activity & no activity & no activity & - \\
\hline
\end{tabular}

${ }^{a}$ The kinetic parameters were obtained using non-linear least-squares fitting of the experimental data to the Michaelis-Menten equation in SigmaPlot 2006 (version 10.0 for Windows). ${ }^{b}$ When limited substrate solubility prevented saturation of the enzyme, $k_{\text {cat }} / K_{m}$ was calculated from the slope of the Michaelis-Menten plot where the rate is linearly dependent on the substrate concentration. N/A not applicable 


\section{Discussion}

\section{Literature survey}

A literature survey yielded 13 examples of enantioselective bioreductions of 2-phenylpropanal using free or immobilized enzymes (Table 4). Previous studies investigated bioreduction catalysts (soluble enzymes discussed in entries $1-5,8-10,12,13$; immobilized enzymes in

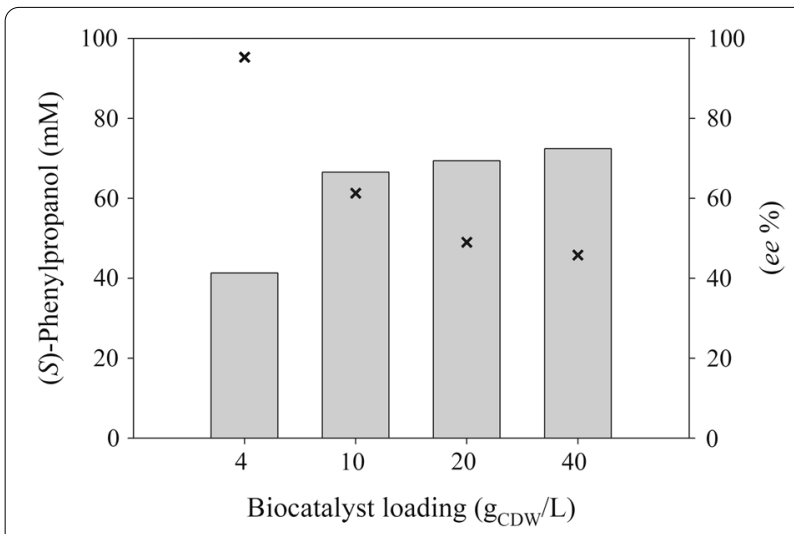

Fig. 2 Conversions and product enantiopurities for the reduction of $100 \mathrm{mM}$ racemic 2-phenylpropanal using a lyophilized and rehydrated whole-cell catalyst. The effects of catalyst loading on product concentration ( $\mathrm{mM}$, bars) and product ee-value (\%, crosses) were studied. The $\mathrm{NAD}^{+}$concentration was $6 \mathrm{mM}$ and the reaction time was $24 \mathrm{~h}$. (The details are summarized in the Supplementary data, Table S1) entries 6,7,11) in the kinetic resolution of rac-2-phenylpropanal (entries 4, 6-11). Most enantioselective enzymes preferred the $(S)$-aldehyde (entries 1-8, 10). Rocha-Martín et al. [13] reported that the ADH from Thermus thermophilus HB27 exhibits anti-Prelog specificity (entry 11). Dong et al. [8] used directed evolution on an ADH from Thermoanaerobacter brockii, which displayed moderate Prelog-type selectivity, to improve the formation of $(S)$ - and $(R)$-alcohols (entries 8, 9). HLADH was used in most studies due to its enantioselectivity, substrate tolerance up to a concentration of $165 \mathrm{mM}$, and usefulness in coupled substrate strategies (oxidation of cheap alcohols for NADH-recycling). Most other selective ADHs stem from thermophilic organisms and display intrinsically high stability in adverse reaction media. The low number of reported enzymes and the low obtained product titers indicated that the reactive aldehyde substrate generally inactivates the enzymes [29]. Remarkably, the often-used host $E$. coli shows native activity towards 2-phenylpropanal (entry 14) [30], which was traced back to the tetrameric ADH of E. coli (entry 12) [1,31]. Buffered solutions containing water-soluble co-solvents (also used as sacrificial substrates for NADH recycling) were also used in many studies, whereby the aqueous phase enabled the racemization of the substrate. The highest published product concentration of $82 \mathrm{mM}$ was achieved in a 47:63 buffer/isopropyl ether mixture (entry 4) [16].

Table 3 Conversions and product ee-values for the reduction of rac-2-phenylpropanal using a lyophilized and rehydrated whole-cell biocatalyst. The effects of catalyst loading, substrate concentration, coenzyme concentration and the addition of HBC (2-hydroxypropyl- $\beta$-cyclodextrin) were investigated. ${ }^{\text {a,b }}$

\begin{tabular}{|c|c|c|c|c|c|}
\hline $\begin{array}{l}\text { Catalyst loading } \\
\left(\mathbf{g}_{\mathrm{CDW}} / \mathrm{L}\right)\end{array}$ & $\begin{array}{l}\text { rac-2-Phenylpropanal } \\
\text { (M) }\end{array}$ & $\begin{array}{l}\mathrm{NAD}^{+} \\
(\mathrm{mM})\end{array}$ & $\begin{array}{l}\mathrm{HBC} \\
(\mathrm{mM})\end{array}$ & Phenylpropanol (mM) & $\begin{array}{l}\text { ee of }(S) \text { - } \\
\text { Phenylpropanol } \\
(\%)\end{array}$ \\
\hline 20 & 1 & 3 & 0 & $234 \pm 16$ & $95.1 \pm 0.0$ \\
\hline 20 & 1 & 3 & 38 & $401 \pm 10$ & $94.1 \pm 0.0$ \\
\hline 20 & 1 & 3 & 75 & $406 \pm 2$ & $93.3 \pm 0.1$ \\
\hline 40 & 1 & 3 & 0 & $506 \pm 14$ & $92.2 \pm 0.0$ \\
\hline 40 & 1 & 6 & 0 & $619 \pm 24^{c}$ & $93.3 \pm 1.1^{c}$ \\
\hline 40 & $1 \mathrm{M}$ fed-batch & 6 & 0 & $611 \pm 12$ & $94.0 \pm 0.1$ \\
\hline 40 & 1 & 8 & 0 & $662 \pm 9$ & $94.1 \pm 0.1$ \\
\hline 40 & 1 & 10 & 0 & $843 \pm 31$ & $93.1 \pm 0.2$ \\
\hline 40 & 1 & 12 & 0 & $839 \pm 36$ & $92.9 \pm 0.1$ \\
\hline 40 & 1 & 14 & 0 & $765 \pm 31$ & $92.3 \pm 0.1$ \\
\hline 40 & 1 & 6 & 38 & $634 \pm 8$ & $94.3 \pm 0.2$ \\
\hline 40 & 1 & 6 & 75 & $598 \pm 7$ & $92.9 \pm 0.2$ \\
\hline 40 & 2 & 6 & 0 & $571 \pm 10$ & $95.4 \pm 0.1$ \\
\hline 40 & 2 & 6 & 38 & $633 \pm 2$ & $93.4 \pm 0.5$ \\
\hline 40 & 2 & 6 & 75 & $637 \pm 22$ & $92.2 \pm 0.2$ \\
\hline
\end{tabular}

${ }^{a}$ Reaction time $48 \mathrm{~h} .{ }^{\text {b}}$ The data represent the mean values and deviations from the mean of two reaction replicates. ${ }^{\circ}$ The data represent the mean values and standard deviations of 7 reaction replicates 


\section{Reduction of rac-2-phenylpropanal by $\mathrm{CtXR}$ variants}

We investigated five enzyme variants with single point mutations in close vicinity to the stereocenter of 2-phenylpropanal (Table 1). Replacement of the charged Asp51 with alanine substantially improved the enzyme's activity. The catalytic efficiency increased 215-fold for rac-2-phenylpropanal and 270-fold for the $(S)$-aldehyde compared to the wild type (Table 1 ). Similarly, the catalytic efficiency in the reduction of $o$-chloroacetophenone was improved 13-times by the D51A mutation [19], which was accompanied by a 50 -fold decrease in the conversion of the native substrate xylose. Replacement of aspartate with alanine appears to be a general strategy for improving the activity of CtXR and its homologues towards hydrophobic substrates [24]. By contrast, the W24F and W24Y mutations diminished the reductase activity in the conversion of rac-2-phenylpropanal to 6 and $8 \%$ of the value of wild-type $C t X R$, respectively (Table 1). Reduced enzyme activities (with higher $K_{\mathrm{m}}{ }^{-}$ values) towards rac-2-phenylpropanal were observed following the removal of the bulky Trp-24, which confirmed a general role of Trp-24 in the efficient conversion of aldehydes. The effects of these single point mutations on the enantioselectivity are discussed below.

\section{Enantioselectivity of $\mathrm{CtXR}$ variants towards 2-phenylpropanal}

The enantioselectivity of an enzyme is generally defined by the ratio of catalytic efficiencies for the two enantiomers $\left(\mathrm{E}=\left(k_{\mathrm{cat}} / K_{\mathrm{m}, \mathrm{S}}\right) /\left(k_{\mathrm{cat}} / K_{\mathrm{m}, \mathrm{R}}\right) \quad\right.$ [32]. The published racemization velocity $\left(k_{\text {rac }}\right)$ of 2-phenylpropanal is $75 \cdot 10^{-}$ ${ }^{6} \mathrm{~s}^{-1}$, corresponding to a half-life $\left(\mathrm{t}_{1 / 2}\right)$ of $\sim 2 \mathrm{~h}$ [15]. The relatively slow racemization should generally enable the determination of the $k_{\text {cat }} / K_{\mathrm{m} \text {,enantiomer }}$ values using enzymatic assays that can be completed in $5 \mathrm{~min}$. However, we observed slow racemization of the pure enantiomers during frozen storage at $-18{ }^{\circ} \mathrm{C}$ (data not shown). Hence, the enantioselectivities shown in Table 1 (expressed as the $\left(k_{\mathrm{cat}} / K_{\mathrm{m}, \mathrm{S}}\right) /\left(k_{\mathrm{cat}} / K_{\mathrm{m}, \mathrm{rac}}\right)$ ratios $)$ represent approximate values that are still useful to guide enzyme selection and reaction optimization. The wild type showed a preference for the $(S)$-aldehyde (ratio of 1.23). The D51A mutant showed a markedly stronger preference for the $S$-enantiomer than the N310A mutant (1.54 vs. 0.77). Asp-51 and Asn-310 are on opposite sides of the substrate-binding pocket (Fig. 3). Asp-51 is suggested to interact with the hydroxyl groups of the natural substrate xylose at C-3, C-4 and C-5, while Asn-310 interacts with the hydroxyl group at C-2 [23] (Fig. 3A). Docking simulations of wild-type $C t \mathrm{XR}$ (in complex with $\mathrm{NAD}^{+}$) with $(S)$ - and $(R)$-2-phenylpropanal are shown in Fig. 3B. Differential positions of the $(S)$ - and $(R)$-2-phenylpropanal enantiomers provide a possible explanation for the enantiomer preferences of the mutants. Replacement of Asp-51 with alanine might introduce an interaction between the alanine and the phenyl-ring of (S)-2-phenylpropanal (Fig. 3C). After replacement of Asn-310 with alanine, this interaction between alanine and the phenylring of $(R)$-2-phenylpropanal becomes even more plausible (Fig. 3D). The W24F and W24Y mutants showed $\left(k_{\text {cat }} / K_{\mathrm{m}, \mathrm{S}}\right) /\left(k_{\mathrm{cat}} / K_{\mathrm{m} \text { rac }}\right)$ ratios of $\sim 0.91$ (Table 1$)$. along with an approximately $\geq$ tenfold reduction of their catalytic efficiency. Lower activities (with higher $K_{\mathrm{m}}$-values) and a preference for the $(R)$-aldehyde might indicate an even poorer interaction between the aromatic rings of phenylalanine or tyrosine and the aldehyde proton of the $(S)$-substrate. In conclusion, the D51A mutant of $C t \mathrm{XR}$ was identified as a variant with improved catalytic efficiency and enantioselectivity, exhibiting a 40-fold higher $k_{\text {cat }}$ and a $\sim 30$-fold smaller $K_{\mathrm{m}}$ for the racemic substrate compared to published values for variants of the ADH from Thermoanaerobacter brockii [8].

\section{Catalyst stabilization}

CtXR is generally known to have low substrate tolerance, with half-lives in the presence of 5 to $10 \mathrm{mM} o$-chloroacetophenone or 1-(2-chlorophenyl)ethanol shorter than $3 \mathrm{~min}$. In the case of $o$-chloroacetophenone and its reaction product, the unfavorable $\log \mathrm{P}$ values $(\sim 2)$ are at least partially responsible for the fast enzyme deactivation. Integration of this oxidoreductase into whole-cell biocatalysts (E. coli, S. cerevisiae, C. tenuis) was previously shown to substantially stabilize the enzyme, resulting in > tenfold improvements of the product titer [34]. Reactive aldehydes are known to form adducts with lysine, histidine and cysteine residues of proteins [29]. Fast enzyme deactivation by 2-phenylpropanal and $o$-chloroacetophenone might therefore be caused by different mechanisms. The use of whole cells provided an extreme case of catalyst stabilization in the presence of 2-phenylpropanal, since the isolated enzyme was deactivated by $0.5 \mathrm{mM}$ aldehyde whereas the whole-cell catalyst was able to tolerate and convert $1 \mathrm{M}$ substrate. Stabilization of the enzyme by whole cells and cell debris was previously reported for the synthesis of $(R)$-phenylacetyl carbinol from benzaldehyde and pyruvate using a pyruvate decarboxylase from Candida utilis. The stabilization was ascribed to membrane components that form a microenvironment around the enzyme and thereby decrease aldehyde transfer to the enzyme, protecting it from deactivation at the aqueous/organic interphase [35]. The addition of cyclodextrin (HBC), which was previously shown to boost the reduction of $o$-chloroacetophenone, only had a minor effect on the lyophilized $E$. coli cells used in this study. Catalyst stabilization by cell components was apparently dominant, especially at the higher catalyst 


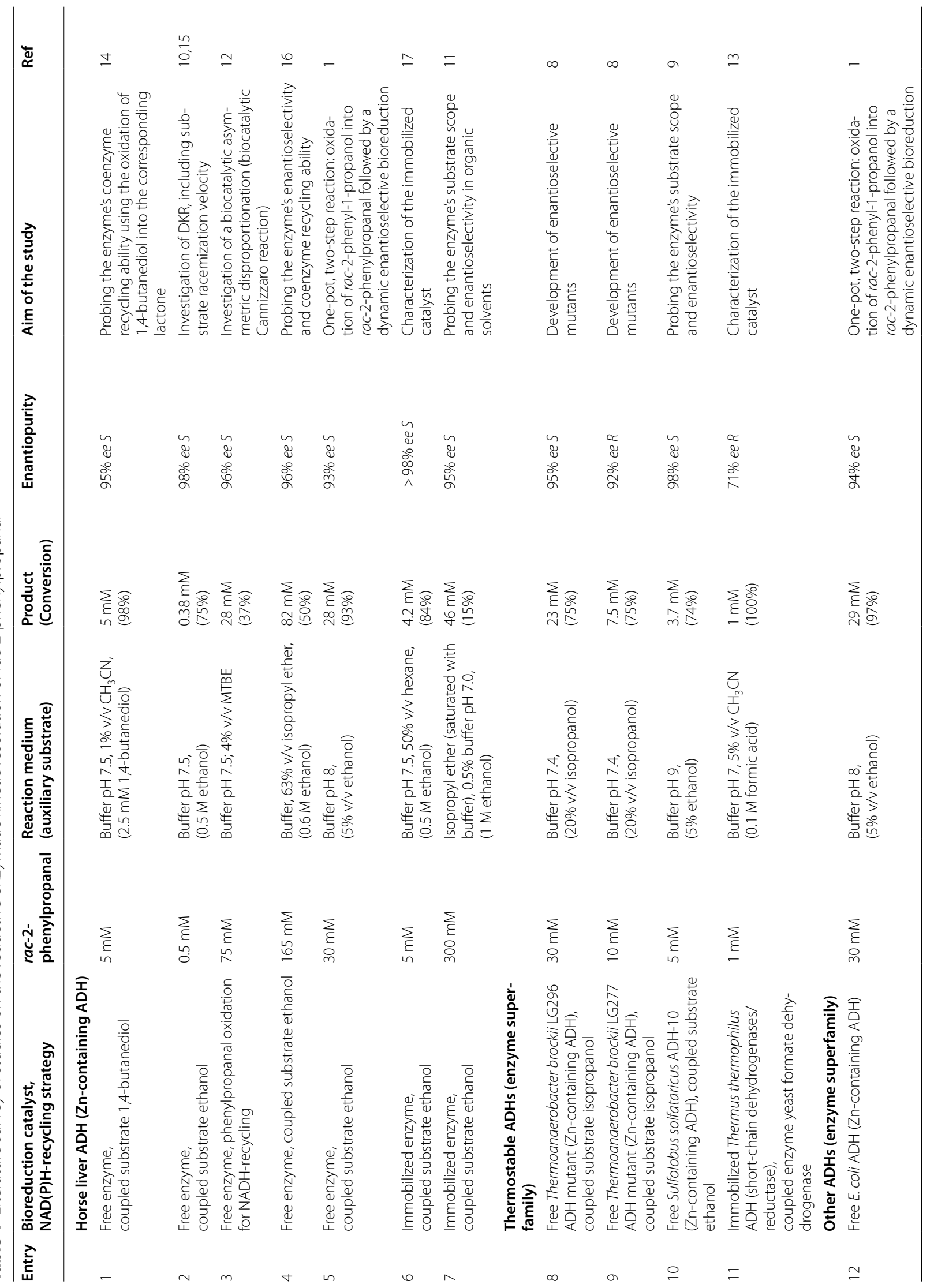




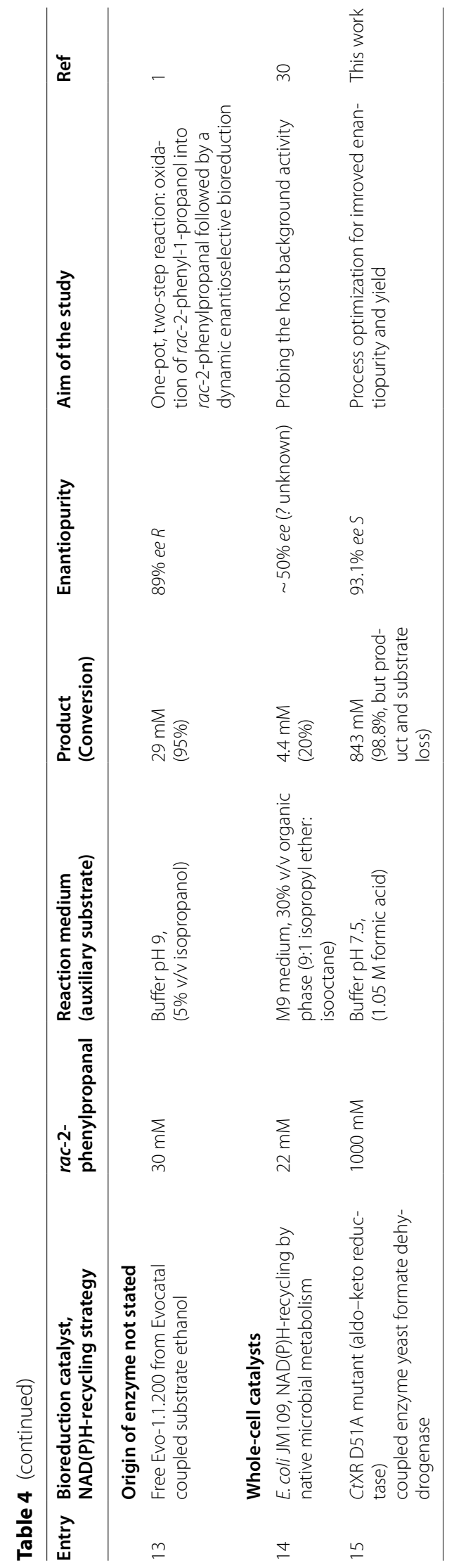


loading of $40 \mathrm{~g}_{\mathrm{CDW}} / \mathrm{L}$, and the addition of $\mathrm{HBC}$ only increased the product concentration at a lower catalyst loading of $20 \mathrm{~g}_{\mathrm{CDW}} / \mathrm{L}$ (Table 3).

\section{Product enantiopurity and concentration}

Generally, an enzyme with higher enantioselectivity will generate a product with higher enantiomeric excess. In the case of an enzyme that converts one enantiomer much faster than the other, the product of the initial stage of the conversion at a high substrate and low product concentration will show high enantiopurity, whereas a decrease is expected during the course of the reaction (expressed in the Chen equation, [32]). Hence, product enantiopurity depends on the enantioselectivity of the reductase and on the availability (concentrations) of both substrate enantiomers. DKR strategies make use of the relatively fast racemization of 2-aryl-1-propanals (reviewed in Kourist et al. [4]). Optimally, there is an equal availability of both substrate enantiomers during the entire DKR reaction (both substrate enantiomers are present in equal concentrations). However, in the present case, a relatively high reductase activity was used to compensate for fast catalyst deactivation, leading to a tradeoff between the enantiomeric purity and final titer of the product (Fig. 2). A dependence of product enantiopurity on reaction progress, especially at high enzyme loading, was also reported in other studies on DKR. The substrate racemization velocity was previously identified as the main factor limiting product enantiopurity [12]. Here, the substrate-to-catalyst ratio was identified as the main factor determining product enantiopurity. The $e e$ value of the product showed the expected dependence on the substrate-to-catalyst ratio (expressed as $\mathrm{g}_{\text {substrate }} / \mathrm{g}_{\mathrm{CDW}}$ in Fig. 4). The highest ee-values of 95.3 and 95.4 were obtained for the conversions of 100 and $2 \mathrm{M} \mathrm{rac-2-phe-}$ nylpropanal by 4 and $40 \mathrm{~g}_{\mathrm{CDW}} / \mathrm{L}$, respectively. However, the reduction of $2 \mathrm{M}$ substrate was compromised by a low conversion ratio ( $\sim 30 \%$, Table 3$)$. Thus, a compromise between product enantiopurity and the conversion ratio had to be found. Overall, the main limiting factors were substrate racemization velocity, catalyst stability and catalyst loading, with higher catalyst loading leading to a loss of the hydrophobic product in the biomass fraction during downstream processing [36].

\section{Conclusions}

Detailed optimization of a reductive enzymatic dynamic kinetic resolution of racemic 2-phenylpropanal yielded $843 \mathrm{mM}(115 \mathrm{~g} / \mathrm{L})(S)$-2-phenylpropanol with 93\% ee. The multilevel strategy included rational mutagenesis of $C t \mathrm{XR}$ for improved enzyme activity and enantioselectivity, the use of an E. coli whole-cell catalyst for enzyme stabilization and coenzyme recycling, as well as the optimization of the substrate-to-catalyst ratio to increase the enantiopurity and final titer of the product. The use of the whole-cell catalyst led to a remarkable $>1000$-fold improvement of the product concentration, indicating strong enzyme stabilization by cellular components. The most important factor for obtaining high enantiopurities and product concentrations was the ratio of substrate to catalyst (Fig. 4). High reduction velocities led to high conversions at the expense of lower product enantiopurities. The conversion with a catalyst loading of $40 \mathrm{~g}_{\mathrm{CDW}}$, $10 \mathrm{mM} \mathrm{NAD}^{+}$and $1 \mathrm{M}$ substrate was identified as a suitable compromise, affording $843 \mathrm{mM}(S)$-phenylpropanol with $93.1 \%$ ee (Table 3).

\section{Materials and methods}

\section{Chemicals, enzymes and strains}

Racemic 2-phenylpropanal (98\%), racemic 2-phenylpropanol (97\%), acetophenone (99\%) and racemic 1-phenylethanol $(\geq 98 \%)$ were purchased from Sigma-Aldrich/ Fluka (Vienna, Austria); (S)-2-phenylpropanal (95\%) and (R)-2-phenylpropanal (95\%) were from Accela (Prien Chiemsee, Germany); 2-hydroxypropyl- $\beta$-cyclodextrin (HBC, batch number OH053931501) was from Carbosynth (Berkshire, UK); $\mathrm{NAD}^{+}(98 \%)$, acetonitrile $(\geq 99)$ and ethyl acetate $(\geq 99,9 \%)$ were from Roth (Karlsruhe, Germany). Other chemicals were from Sigma-Aldrich/ Fluka or Roth, and were of the highest purity available. Materials for genetic modification were reported elsewhere [24]. The used reductases were the wild type and single-point mutants of Candida tenuis xylose reductase (CtXR wild-type GenBank ID AF074484). Site-directed mutagenesis for the construction of the CtXR mutants D51A, W24F, W24Y, N310A, and N310D was carried out using inverse PCR as described elsewhere [24]. The protein expression of CtXR (wild-type and mutants D51A, W24F, W24Y, N310A, N310D) was described previously [24]. An E. coli Rosetta2 strain co-expressing CtXR D51A and CbFDH (GenBank ID AJ011046) was used in the bioreductions. The construction of the co-expression strain was previously described by Rapp et al. [19]. Cultivation of the co-expression strain was described previously [19], and is summarized in the Additional file 1 . The biomass was frozen at $-20^{\circ} \mathrm{C}$, lyophilized (Christ $\alpha 1-4$ lyophilizer from Braun Biotech International) and stored at $-20{ }^{\circ} \mathrm{C}$.

\section{Enzyme kinetics}

Steady state kinetic parameters for the NADH-dependent reduction of 2-phenylpropanal by $C t \mathrm{XR}$ variants were determined spectrophotometrically as described earlier [24]. The solubility of 2-phenylpropanal in water was increased to $0.5 \mathrm{mM}$ by the addition of $25 \% \mathrm{v} / \mathrm{v}$ DMSO. 


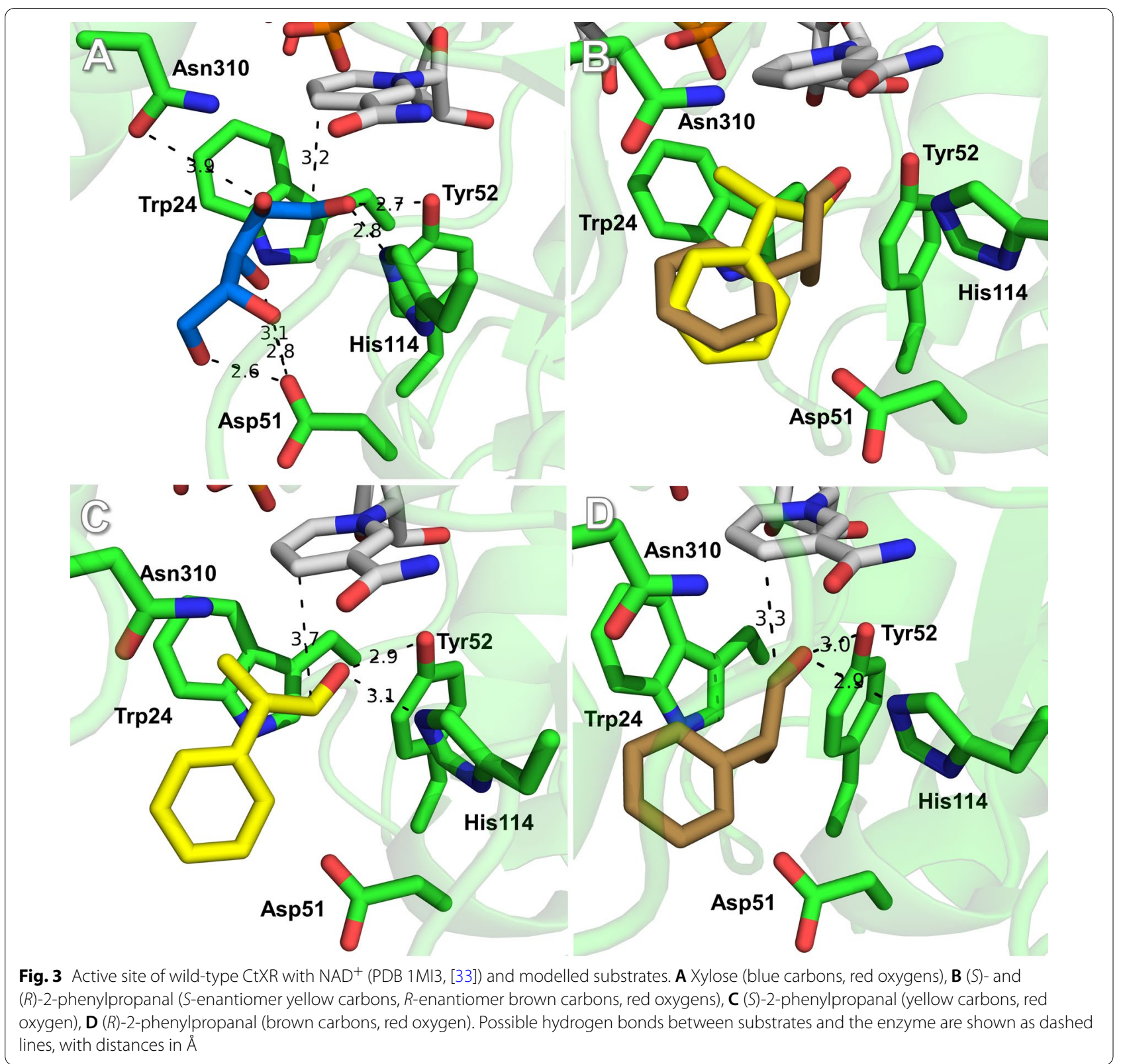

Substrate solutions were freshly prepared and immediately used to avoid non-enzymatic decomposition or racemization in aqueous solution in the case of $(S)$-2-phenylpropanal. A typical measurement period was $5 \mathrm{~min}$. Non-specific background activity was taken into account by measuring blank mixtures. The added DMSO had no effect on the enzyme's activity with the natural substrate D-xylose.

\section{Bioreduction of racemic 2-phenylpropanal} Reduction by the isolated CtXR D51A

Racemic 2-phenylpropanal was dissolved in DMSO prior to dilution into $50 \mathrm{mM}$ potassium phosphate buffer, $\mathrm{pH}$
7.0 , to a final DMSO concentration of $25 \%$. The substrate (final concentration $0.5 \mathrm{mM}$ ) was incubated at $25{ }^{\circ} \mathrm{C}$ in the presence of $0.2 \mathrm{mM}$ NADH and $C t$ XR D51A for $2 \mathrm{~h}$. For time-course analysis, $100-\mu \mathrm{L}$ samples were taken from the reaction mixtures (final reaction volume $1.5 \mathrm{~mL}$ ) at the specified timepoints. All samples were diluted 1:1 with acetonitrile and centrifuged prior to analysis by chiral HPLC.

\section{Whole-cell bioreductions}

Lyophilized biomass ( $40 \mathrm{mg}$ or $80 \mathrm{mg}$ ) was rehydrated in $1 \mathrm{~mL}$ of potassium phosphate buffer (100 mM, pH 6.2) 


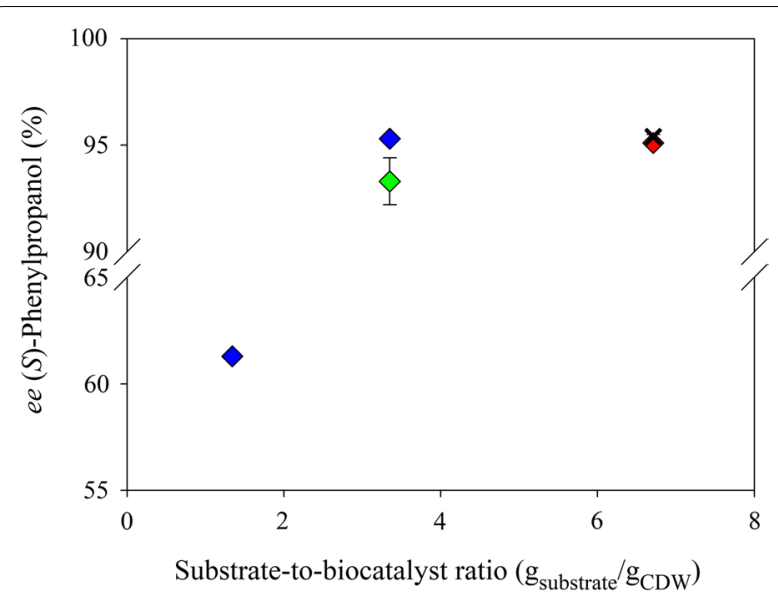

Fig. 4 Effect of the substrate-to-biocatalyst ratio (whole-cell biocatalyst) on product enantiopurity. Blue diamonds show the conversion of $100 \mathrm{mM}$ rac-2-phenylpropanal with 4 and $10 \mathrm{~g}_{\mathrm{CDW}}$ biocatalyst, green diamonds with $1 \mathrm{M}$ substrate and $40 \mathrm{~g}_{\mathrm{CDW}}$, red diamonds with $1 \mathrm{M}$ substrate and $20 \mathrm{~g}_{\mathrm{CDW}}$, black crosses with $2 \mathrm{M}$ substrate and $40 \mathrm{~g} \mathrm{CDw}$. (Data with error bars from reactions with $6 \mathrm{mM} \mathrm{NAD}^{+}$are depicted. See also the section Optimization of 2-phenylpropanal bioreduction, Table 3)

containing $\mathrm{NAD}^{+}(0.5-14 \mathrm{mM})$ and sodium formate (50 mM, excess over substrate) in $2 \mathrm{~mL}$ Eppendorf tubes. Activities of the whole biomass, measured after cell lysis and protein extraction for rac-2-phenylpropanal reduction and formate dehydrogenase were 2200 and $154 \mathrm{U} /$ $\mathrm{g}_{\mathrm{CDW}}$, respectively [19]. rac-2-phenylpropanal reduction activity was determined at $0.5 \mathrm{mM} \mathrm{rac}$-2-phenylpropanal in $50 \mathrm{mM}$ potassium phosphate buffer, $\mathrm{pH} 7.0$, with $25 \%$ DMSO. The rehydrated biomass (containing $\mathrm{NAD}^{+}$and sodium formate, volume of the biomass slurry $\leq 50 \% \mathrm{v} / \mathrm{v}$ of the total bioreduction mixture) was combined with the substrate and filled up to a total working volume of $1 \mathrm{~mL}$. In case of cyclodextrin-aided conversions, HBC and substrate were weighed separately in Eppendorf tubes containing $50 \mu \mathrm{L}$ buffer, followed by vortexing prior to addition to the biomass. Eppendorf tubes were sealed with parafilm and vortexed until the mixtures completely emulsified. The mixtures were reacted for 24 or $48 \mathrm{~h}$ at room temperature using an end-over-end rotator $(30 \mathrm{rpm})$. The fed-batch bioreductions were started as batch reactions with $330 \mathrm{mM}$ substrate, $6 \mathrm{mM} \mathrm{NAD}^{+}$ and $40 \mathrm{~g}_{\mathrm{CDW}} / \mathrm{L}$. $50 \mu \mathrm{L}$ rac-2-phenylpropanal, and were fed after 2 and $4 \mathrm{~h}$ to reach a total substrate concentration corresponding to $1 \mathrm{M}$. The reaction was carried out for $48 \mathrm{~h}$.

\section{Substrate/product recovery}

For recovery experiments at substrate/product concentrations of $1 \mathrm{M}$, reaction mixtures containing 20 or 40 $\mathrm{g}_{\mathrm{CDW}} / \mathrm{L}$ catalyst were prepared without adding $\mathrm{NAD}^{+}$.
The samples were incubated under the same conditions as used for biotransformations and extracted following the procedure described in Sect. Analytical methods. Substrate/product recovery was performed in duplicates.

\section{Analytical methods}

For HPLC and GC analyses, ethyl acetate $(1 \mathrm{~mL})$ was added to $1 \mathrm{~mL}$ of a reaction mixture in a $2 \mathrm{~mL}$ Eppendorf tube. The tubes were vortexed and the mixtures transferred into $15 \mathrm{~mL}$ Sarstedt tubes. The tubes were then filled up to $10 \mathrm{~mL}$ with ethyl acetate, vortexed and centrifuged for $15 \mathrm{~min}, 25^{\circ} \mathrm{C}$ and $3220 \mathrm{~g}$ for extraction. Final dilutions in ethyl acetate contained $5 \mathrm{mM}$ substrate/ product. For NMR analyses, substrate/product present in ethyl acetate after extraction was transferred into round-flasks and evaporated under reduced pressure. The isolated substrate/product was directly dissolved in deuterated methanol $(20 \mu \mathrm{L}$ substrate/product $+680 \mu \mathrm{L}$ solvent).

\section{Chiral HPLC analysis}

HPLC analysis was performed using a Merck-Hitachi LaChrom HPLC system equipped with a Merck L-7490 RI detector, an L-7400 UV-detector, a reversed phase Chiralpak ${ }^{\circledR}$ AD-RH column (from Daicel, obtained at Sigma Aldrich, Vienna, Austria) and a thermostat column oven $\left(40{ }^{\circ} \mathrm{C}\right)$. The mobile phase was composed of $25 \%$ acetonitrile in $\mathrm{ddH}_{2} \mathrm{O}$ at a flowrate of $30 \mathrm{~mL} /$ min. HPLC standard curves were prepared using racemic product at $0.1,0.5,1,5$, and $10 \mathrm{mM}$ concentrations. Peak areas at corresponding retention times were used to calculate the concentrations. The enantiomeric excess of the major product $(S)$-2-phenylpropanol was calculated using the formula $e e=(S$-alcohol $-R$-alcohol $) /$ $(S$-alcohol $+R$-alcohol). The retention times and chromatograms of authentic standards (main products $((S)$ 2-phenylpropanol, (R)-2-phenylpropanol), by-products (acetophenone, phenylethanol) were summarized in the Additional file 1: Sect. 4. The aldehydes gave too broad peaks on HPLC and were quantified by GC-FID.

\section{Chiral GC-FID analysis}

GC analysis was performed on an Agilent 7890A GC with FID detection [12] equipped with a chiral Hydrodex ${ }^{\circledR}-\beta$ TBDAc column with $25 \mathrm{~m}$ length and an inner diameter of $0.25 \mathrm{~mm}$ (from Macherey-Nagel obtained from FisherScientific, Austria, Vienna). The carrier gas was $\mathrm{H}_{2}$ with a flow of $1 \mathrm{~mL} / \mathrm{mi}$, the injection volume was $5 \mu \mathrm{L}$, the split ratio was $50: 1$, the inlet temperature $230{ }^{\circ} \mathrm{C}$, and the detector temperature $250{ }^{\circ} \mathrm{C}$. The following temperature program was used for the separation of analytes: $110^{\circ} \mathrm{C} /$ hold $10 \mathrm{~min} ; 2{ }^{\circ} \mathrm{C}$ per min to $123{ }^{\circ} \mathrm{C} /$ hold $3 \mathrm{~min} ; 10^{\circ} \mathrm{C}$ per min to $200{ }^{\circ} \mathrm{C} /$ hold $1 \mathrm{~min}$. The retention times and 
chromatograms of authentic standards (main products ((S)-2-phenylpropanol, $(R)$-2-phenylpropanol), substrate ((S)-2-phenylpropanal, $(R)$-2-phenylpropanal) by-products (acetophenone, phenylethanol) are summarized in the Additional file 1: Sect. 5.

\section{NMR analysis}

${ }^{1} \mathrm{H}-\mathrm{NMR}$ spectra of isolated substrate/product from biotransformations (78\% conversion) were recorded using a $300 \mathrm{MHz}$ Bruker NMR unit $\left(300 \mathrm{MHz}\right.$ for $\left.{ }^{1} \mathrm{H}\right)$ at $300 \mathrm{~K}$. Chemical shifts $(\delta)$ were depicted in ppm relative to the resonance of the solvent (MeOD) (see also Additional file 1: Sect. 6).

\section{Enzyme-substrate docking simulations}

PyMOL Molecular Graphics System (Open-Source, Schrödinger, LLC) was used for enzyme/ligand structure depictions. Ligand docking simulations were performed in YASARA (YASARA Biosciences GmbH, Vienna, Austria) using AutoDock Vina [37] with standard parameters.

\section{Abbreviations}

ADH: Alcohol dehydrogenase; CbFDH: Candida boidinii Formate dehydrogenase; CtXR: Candida tenuis Xylose reductase; DKR: Dynamic kinetic resolution: $\mathrm{g}_{\mathrm{CD}}$ : Cell dry weight in gram; HBC: 2 -Hydroxypropyl- $\beta$-cyclodextrin; HLADH: Horse liver alcohol dehydrogenase; rac: Racemic.

\section{Supplementary Information}

The online version contains supplementary material available at https://doi. org/10.1186/s12896-021-00715-5.

Additional file 1. 1. Biomass production. 2. Reduction of rac-2-phenylpropanal by isolated CtXR D51A. Time course of the reduction of $0.5 \mathrm{mM}$ substrate with $240 \mathrm{U} / \mathrm{mL}$ of isolated CtXR D51A. 3. Biotransformation of rac-2-phenylpropanal. Conversions and product ee-values from the reduction of $100 \mathrm{mM}$ rac-2-phenylpropanal using a lyophilized and rehydrated whole-cell catalyst. Effects of catalyst loading. Conversions and product ee-values from the reduction of $1 \mathrm{M} \mathrm{rac}$-2-phenyl-propionaldehyde using a lyophilized and rehydrated whole-cell catalyst. Effects of catalyst loading $\left(20 \mathrm{~g}_{\mathrm{CDW}} / \mathrm{L}, 40 \mathrm{~g}_{\mathrm{CDW}} / \mathrm{L}\right)$ and coenzyme concentration (NAD $\left.+3-14 \mathrm{mM}\right)$. (The data are based on HPLC measurements, Table 3). 4. Reversed phase chiral HPLC. Separation of main products and by-products by HPLC. UV traces and retention times for rac-2-phenylpropanal, acetophenone, 1-phenylethanol, $(R, S)$-2-phenylpropanol, reaction buffer with $\mathrm{NAD}^{+}$ reaction buffer, bioreduction sample of $1 \mathrm{M}$ rac-2-phenylpropanal reacted with $40 \mathrm{~g} \mathrm{cow} / \mathrm{L}$ and $6 \mathrm{mM} \mathrm{NAD}{ }^{+}$. 5. Chiral GC-FID. GC traces and retention times for main products, by-products and bioreduction replicates $(N=6)$ of $1 \mathrm{M}$ rac-2-phenylpropanal reacted with $40 \mathrm{~g} \mathrm{cow} / \mathrm{L}$ and $6 \mathrm{mM} \mathrm{NAD}+.6$. ${ }^{1} \mathrm{H}$-NMR. ${ }^{1} \mathrm{H}$-spectrum of the isolated product from a reaction with $78 \%$ analytical yield (HPLC) from $1 \mathrm{M} \mathrm{rac}$-2-phenylpropanal reacted with 40 $\mathrm{g}_{\mathrm{CDW}} / \mathrm{L}$ and $6 \mathrm{mM} \mathrm{NAD}{ }^{+}$.

\section{Acknowledgements}

We thank Drs. Alexander Denning and Alexander Lepak for discussions and support with $\mathrm{GC}$ and ${ }^{1} \mathrm{H}-\mathrm{NMR}$ analysis.

\section{Authors' contributions}

CR performed and analyzed the bioreduction experiments and was involved in experimental design and manuscript preparation. SP-M performed experiments with isolated enzymes (kinetics, bioreductions). ET was involved in experimental design and bioreduction analyses. BN made contributions to study-conception, interpretation of the data and revised the manuscript. RK conceptualized the study, contributed to the design of experiments, interpreted the data and drafted the manuscript. All authors read and approved the final manuscript.

\section{Funding}

The COMET center ACIB (funding to BN): Next Generation Bioproduction was funded by BMK, BMDW, SFG, Standortagentur Tirol, Government of Lower Austria und Vienna Business Agency in the framework of COMET_Competence Centers for Excellent Technologies. The COMET-Funding Program was managed by the Austrian Research Promotion Agency FFG. Role of funding: Experiments with isolated enzymes (kinetics, bioreductions) through the work of SP-M. The funders had no influence on the design and publication of the study.

\section{Availability of data and materials}

The datasets used and/or analyzed during the current study are available in the Supplementary data or from the corresponding author upon reasonable request.

\section{Declarations}

Ethics approval and consent to participate

Not applicable.

\section{Consent for publication}

Not applicable.

\section{Competing interests}

The authors declare that they have no competing interests.

\section{Author details}

${ }^{1}$ Institute of Biotechnology and Biochemical Engineering, Graz University of Technology, NAWI Graz, 8010 Graz, Austria. 'Department of Chemistry, University of Graz, NAWI Graz, Heinrichstrasse 28, 8010 Graz, Austria. ${ }^{3}$ Austrian Centre of Industrial Biotechnology (ACIB), 8010 Graz, Austria.

Received: 13 April 2021 Accepted: 20 September 2021

Published online: 11 October 2021

\section{References}

1. Díaz-Rodríguez A, Ríos-Lombardía N, Sattler JH, Lavandera I, GotorFernández V, Kroutil W, Gotor V. Deracemisation of profenol core by combining laccase/TEMPO-mediated oxidation and alcohol dehydrogenasecatalysed dynamic kinetic resolution. Catal Sci Technol. 2015;5:1443-6. https://doi.org/10.1039/C4CY01351D.

2. Abate A, Brenna E, Fuganti C, Gatti FG, Giovenzana T, Malpezzi L, Serra S. Chirality and fragrance chemistry: stereoisomers of the commercial chiral odorants Muguesia and Pamplefleur. J Org Chem. 2005;70:1281-90. https://doi.org/10.1021/jo048445j.

3. Scognamiglio J, Jones L, Letizia CS, Api AM. Fragrance material review on $\beta$-methylphenethyl alcohol. Food Chem Toxicol. 2012;50:199-203. https://doi.org/10.1016/j.fct.2011.10.023.

4. Kourist R, Domínguez de María P, Miyamoto K. Biocatalytic strategies for the asymmetric synthesis of profens - recent trends and developments. Green Chem. 2011;13:2607-2618; https://doi.org/10.1039/C1GC15162B.

5. Carvalho PO, Cass QB, Calafatti SA, Contesini FJ, Bizaco R. Review- Alternatives for the separation of drug enantiomers: ibuprofen as a model compound. Braz J Chem Eng. 2006;23:291-300. https://doi.org/10.1590/ S0104-66322006000300003.

6. Koul S, Parshad R, Taneja SC, Qazi GN. Enzymatic resolution of naproxen. Tetrahedron Asymmetry. 2003;14:2459-65. https://doi.org/10.1016/ S0957-4166(03)00492-0.

7. Steenkamp L, Brady D. Optimisation of stabilised carboxylesterase NP for enantioselective hydrolysis of naproxen methyl ester. Process Biochem. 2008;43:1419-26. https://doi.org/10.1016/j.procbio.2008.09.001. 
8. Dong Y, Yao P, Cui Y, Wu Q, Zhu D, Li G, Reetz MT. Manipulating the stereoselectivity of a thermostable alcohol dehydrogenase by directed evolution for efficient asymmetric synthesis of arylpropanols. Biol Chem. 2019;400:313-21. https://doi.org/10.1515/hsz-2018-0299.

9. Friest JA, Maezato Y, Broussy S, Blum P, Berkowitz DB. Use of a robust dehydrogenase from an archael hyperthermophile in asymmetric catalysis-dynamic reductive kinetic resolution entry into (S)-Profens. J Am Chem Soc. 2010;132:5930-1. https://doi.org/10.1021/ja910778p.

10. Giacomini D, Galletti P, Quintavalla A, Gucciardo G, Paradisi F. Highly efficient asymmetric reduction of arylpropionic aldehydes by Horse Liver Alcohol Dehydrogenase through dynamic kinetic resolution. Chem Commun. 2007;4038-4040; doi:https://doi.org/10.1039/B712290J.

11. Grunwald J, Wirz B, Scollar MP, Klibanov AM. Asymmetric oxidoreductions catalyzed by alcohol dehydrogenase in organic solvents. J Am Chem Soc. 1986;108:6732-4. https://doi.org/10.1016/s0958-1669(03)00074-0.

12. Tassano E, Faber K, Hall M. Biocatalytic parallel interconnected dynamic asymmetric disproportionation of a-substituted aldehydes: atomefficient access to enantiopure (S)-Profens and Profenols. Adv Synth Catal. 2018;360:2742-51. https://doi.org/10.1002/adsc.201800541.

13. Rocha-Martín J, Vega D, Bolivar JM, Hidalgo A, Berenguer J, Guisán JM, López-Gallego F. Characterization and further stabilization of a new antiprelog specific alcohol dehydrogenase from Thermus thermophilus HB27 for asymmetric reduction of carbonyl compounds. Bioresour Technol. 2012;103:343-50. https://doi.org/10.1016/j.biortech.2011.10.018.

14. Kara S, Spickermann D, Schrittwieser JH, Leggewie C, van Berkel WJH, Arends IWCE, Hollmann F. More efficient redox biocatalysis by utilizing 1,4-butanediol as a "smart cosubstrate." Green Chem. 2013;15:330-5. https://doi.org/10.1039/C2GC36797A.

15. Galletti P, Emer E, Gucciardo G, Quintavalla A, Pori M, Giacomini D. Chemoenzymatic synthesis of (2S)-2-arylpropanols through a dynamic kinetic resolution of 2-arylpropanals with alcohol dehydrogenases. Org Biomol Chem. 2010;8:4117-23. https://doi.org/10.1039/C005098A.

16. Kelemen-Horváth I, Nemestóthy N, Bélafi-Bakó K, Gubicza L. Stereoselective reduction of 2-phenylpropionaldehyde by alcohol dehydrogenase with cofactor regeneration. Chem Papers. 2002;56:52-6.

17. Quaglia D, Pori M, Galletti P, Emer E, Paradisi F, Giacomini D. His-tagged horse liver alcohol dehydrogenase: Immobilization and application in the bio-based enantioselective synthesis of (S)-arylpropanols. Process Biochem. 2013;48:810-8. https://doi.org/10.1016/j.procbio.2013.03.016.

18. Kratzer R, Nidetzky B. Identification of Candida tenuis xylose reductase as highly selective biocatalyst for the synthesis of aromatic a-hydroxyesters and improvement of its efficiency by protein engineering. Chem Commun. 2007;10:1047-9. https://doi.org/10.1039/B616475G.

19. Rapp C, Nidetzky B, Kratzer R. Pushing the limits: Cyclodextrin-based intensification of bioreductions. J Biotechnol. 2021;325:57-64. https://doi. org/10.1016/j.jbiotec.2020.11.017.

20. Couture J-F, Legrand P, Cantin L, Labrie F, Luu-The V, Breton R. Loop relaxation, a mechanism that explains the reduced specificity of rabbit 20alphahydroxysteroid dehydrogenase, a member of the aldo-keto reductase superfamily. J Mol Biol. 2004;339:89-102. https://doi.org/10.1016/j.jmb. 2004.03.035.

21. Krump C, Vogl M, Brecker L, Nidetzky B, Kratzer R. Acceleration of an aldo-keto reductase by minimal loop engineering. PEDS. 2014;27:245-8. https://doi.org/10.1093/protein/gzu021.

22. Qiu S, Cheng F, Jin L-J, Chen Y, Li S-F, Wang Y-J, Zheng Y-G. Co-evolution of activity and thermostability of an aldo-keto reductase KmAKR for asymmetric synthesis of statin precursor dichiral diols. Bioorg Chem. 2020;103: 104228. https://doi.org/10.1016/j.bioorg.2020.104228.

23. Kavanagh KL, Klimacek M, Nidetzky B, Wilson DK. The structure of apo and holo forms of xylose reductase, a dimeric aldo-keto reductase from
Candida tenuis. Biochemistry. 2002;41:8785-95. https://doi.org/10.1080/ 15216540600818143

24. Kratzer R, Leitgeb S, Wilson DK, Nidetzky B. Probing the substrate binding site of Candida tenuis xylose reductase (AKR2B5) with site-directed mutagenesis. Biochem J. 2006;393:51-8. https://doi.org/10.1042/BJ200 50831.

25. Leis D, Lauß B, Macher-Ambrosch R, Pfennig A, Nidetzky B, Kratzer R. Integration of bioreduction and product isolation: Highly hydrophobic co-solvents promote in situ substrate supply and extractive product isolation. J Biotechnol. 2017;257:110-7. https://doi.org/10.1016/j.jbiotec.2016. 11.021 .

26. Fuchs CS, Hollauf M, Meissner M, Simon RC, Besset T, Reek JNH, Riethorst $W$, Zepeck F, Kroutil W. Dynamic kinetic resolution of 2-phenylpropanal derivatives to yield $\beta$-chiral primary amines via bioamination. Adv Synth Catal. 2014;356:2257-65. https://doi.org/10.1002/adsc.201400217.

27. Vogl M, Kratzer R, Nidetzky B, Brecker L. Candida tenuis xylose reductase catalysed reduction of acetophenones: the effect of ring-substituents on catalytic efficiency. Org Biomol Chem. 2011;9:5863-70. https://doi.org/10. 1039/C1OB05510K.

28. Könst $\mathrm{P}$, Merkens H, Kara S, Kochius S, Vogel A, Zuhse R, Holtmann D, Arends IWCE, Hollmann F. Enantioselective oxidation of aldehydes catalyzed by alcohol dehydrogenase. Angew Chemie Int Ed. 2012;51:9914-7. https://doi.org/10.1002/anie.201203219.

29. LoPachin RM, Gavin T. Molecular mechanisms of aldehyde toxicity: a chemical perspective. Chem Res Toxicol. 2014;27:1081-91. https://doi. org/10.1021/t×5001046.

30. Sello G, Orsini F, Bernasconi S, Di Gennaro P. Selective enzymatic reduction of aldehydes. Molecules. 2006;11:365-9. https://doi.org/10.3390/ 11050365.

31. Karlsson A, El-Ahmad M, Johansson K, Shafqat J, Jörnvall H, Eklund H, Ramaswamy S. Tetrameric NAD-dependent alcohol dehydrogenase Chem-Biol Interact. 2003;143-144:239-45.

32. Chen S, Fujimoto Y, Girdaukas G, Sih CJ. Quantitative analyses of biochemical kinetic resolutions of enantiomers. J Am Chem Soc. 1982;104:7294-9. https://doi.org/10.1021/ja00389a064.

33. Kavanagh KL, Klimacek M, Nidetzky B, Wilson DK. Structure of xylose reductase bound to NAD+ and the basis for single and dual co-substrate specificity in family 2 aldo-keto reductases. Biochem J. 2003;373:319-26. https://doi.org/10.1042/bj20030286.

34. Kratzer R, Woodley JM, Nidetzky B. Rules for biocatalyst and reaction engineering to implement effective, $\mathrm{NAD}(\mathrm{P}) \mathrm{H}$-dependent, whole cell bioreductions. Biotechnol Adv. 2015;33:1641-52. https://doi.org/10. 1016/j.biotechadv.2015.08.006.

35. Satianegara G, Rogers PL, Rosche P. Comparative studies on enzyme preparations and role of cell components for $(R)$-phenylacetylcarbinol production in a two-phase biotransformation. Biotechnol Bioeng. 2006;94:1189-95. https://doi.org/10.1002/bit.20959.

36. Lauß B, Rapp C, Leis D, Nidetzky B, Kratzer R. Separation behavior and microstructure of emulsified, two-phasic E. coli bioreaction mixtures. Colloids Interface Sci Commun. 2020;35:100248; doi:https://doi.org/10. 1016/j.colcom.2020.100248.

37. Trott O, Olson AJ. AutoDock Vina: Improving the speed and accuracy of docking with a new scoring function, efficient optimization and multithreading. J Comput Chem. 2009;31:455-61. https://doi.org/10.1002/jcc. 213.

\section{Publisher's Note}

Springer Nature remains neutral with regard to jurisdictional claims in published maps and institutional affiliations. 